\section{Searching for viruses on the Internet}

One does not have to be an expert in microbiology to be acutely aware of the recent outbreaks around the world of emerging infectious diseases such as AIDS, Hantavirus pulmonary syndrome, dengue fever and Ebola hemorrhagic fever. While many of these diseases are labeled exotic and seem to be distant problems, rapid global travel ensures that the outbreak of a deadly disease in a remote location

Internet connection (at the mission hospital in Vanga), and Mongolia, one of the world's remotest nations, proudly switched on its first Internet connection several months ago.

Important infectious diseases monitored by members of ProMED include the illness caused by a newly identified morbillivirus, which resulted in the deaths of several race horses and their trainer in Australia in 1994; the first report of Japanese encephalitis in Australia in April 1995; the outbreak of avian influenza in Mexico; and the Ebola outbreak in Kikwit, Zaire, in early 1995 (during which the number of ProMED subscribers almost doubled). Information on all aspects of emerging

has the potential to be on any country's doorstep within days. "It is obvious that we need a global system of epidemiological surveillance, an 'early warning system,' to counter the emergence of these infections," explains Stephen S. Morse, assistant professor of virology at the Rockefeller University. At the recent American Association for the Advancement of Science meeting in Baltimore, Morse presented details of ProMED (Program for Monitoring Emerging Diseases), an effort whose most successful project to date uses electronic mail via the Internet to communicate information globally on possible infectious disease threats.

ProMED was originally launched in 1993 under the auspices of the Federation of American Scientists (FAS) at a meeting in Geneva cosponsored by the World Health Organization (WHO), The ProMED e-mail network, started in August 1994, now boasts 3,500 subscribers in more than 100 countries. More than half of subscribers are from the United States; however, increasing awareness of ProMED has started to swell the numbers of subscribers from developing nations. Although often lacking the infrastructure necessary to maintain sophisticated telecommunications systems, developing nations are quickly realizing the cost-effectiveness of e-mail communication with the rest of the world. Zaire now boasts one infectious diseases are discussed through ProMED's e-mail activity, including reports of epidemics, discussion of methods to improve both surveillance and response at the local level, and news of breakthroughs in molecular diagnostics.

Although ProMED's e-mail project has been successful and effective, Morse admits that it is only a first step in the overall global surveillance plans recommended at the Geneva meeting. Among those recommendations are plans for a network of sentinel disease surveillance centers, connected with central hospitals in strategic tropical cities. Each sentinel center is envisioned as a clinical base equipped with adequate laboratory facilities and having epidemiological capabilities and staff trained in the identification of local patients with "unusual" symptoms.

The success of global surveillance strategies ultimately depends on funding. Because WHO has received little more than 50 percent of its expected contributions for the 1995 fiscal year, plans for setting up and staffing local disease surveillance centers in tropical outreaches are likely to remain largely theoretical for a few years to come. However, there is no doubt that ProMED's e-mail network already plays a significant role in the fight against emerging infectious diseases.

ORLA SMITH

\section{DID YOU KNOW?}

\section{UK degrees invalid in India}

As of February 20, Indian doctors returning to their homeland with degrees granted by schools in the United Kingdom will not be allowed to hold jobs in government hospitals. This follows a ruling by the Indian Supreme Court quashing the appointment of Nikil Tandon, an assistant professor at the All India Institute of Medical Sciences in New Delhi, on the grounds that the degree he received from Cambridge University is not recognized by the Medical Council of India (MCl). The court's verdict was rendered in a case filed by Tandon's rival for the job.

Although no UK medical degrees granted after 1979 are recognized by $\mathrm{MCl}$ (a retaliatory move for a similar decision by the British Medical Council the previous year), until now this did not result in refusal of government jobs to UK-trained doctors. However, the new ruling now makes any appointment illegal.

Observers believe the verdict will have a negative impact on India's medical service, particularly in the area of medical specialists, many of whom train in the UK, and who will likely opt to remain there rather than returning to uncertain prospects for practicing medicine.

K.S. JAYARAMAN New Delhi, India

\section{Stamping out breast cancer}

In an effort to

promote early

detection and

screening for breast IMAGE cancer, Postmaster UNAVAILABLE General Marvin

Runyon recently announced the U.S. COPYRIGHT Postal Service's plans REASONS to issue a Breast

Cancer Awareness

stamp during a

national public service campaign.

The National Cancer Institute's Cancer Information Service toll-free number, 1-8004-CANCER, will be printed on the top border of each sheet of stamps as the source for information on breast cancer. The stamp will be officially launched at the 1996 National Race for the Cure in Washington, $D C$, on June 15, and will go on sale nationwide that day. Participating post offices will also offer $\mathrm{NCl}$ educational material.

JENNIFER K. SNOW 